\title{
OVERVIEW OF NON-TRANSPLANT SURGICAL MANAGEMENT OF SHORT BOWEL SYNDROME IN CHILDREN
}

\author{
Robert KÖNIG
}

Szent János Hospital

Budapest, Hungary

Corresponding author: robertkonig@gmail.com

Tel.: + 36703688185

Fax.: + 3614584523

Received: July 4, 2015

Accepted: September 1, 2015

Key words: Short bowel syndrome Autologous reconstructive surgery.

\begin{abstract}
The aim of this study was to review the management of Short Bowel Syndrome, focusing on the current trends regarding non-transplant, autologous surgical reconstructive techniques. Management of severe Short Bowel Syndrome is still one of the greatest challenges of medicine. Paediatricians and paediatric surgeons may face this challenge often because of the relatively common occurrence of necrotizing enterocolitis, intestinal malrotation, volvulus, gastroschisis and "apple peel" atresia. Although the short term results of intestinal transplantation are improving, the long term results are still disappointing. On the other hand an increasing number of patients have been saved through modern intestinal bowel rehabilitation programs and autologous intestinal reconstructive surgeries in the last decade. This review summarizes the main medical elements of these programs, such as the control of gastric hypersecretion, inhibition of intestinal motility, elemental enteral feeding, low fat (home) parenteral nutrition and hormonal enhancement of intestinal adaptation. It focuses on nontransplant surgical management of short bowel patients, such as accurate vascular access surgery, controlled bowel expansion program, extracorporeal stool recycling and intestinal lengthening techniques. Conclusion - Intestinal bowel rehabilitation and autologous intestinal reconstruction should be considered as first line management in short bowel patients. The establishment of national bowel rehabilitation centres should be considered. Intestinal transplantation should be reserved for unsuccessful cases and considered as a last resort.
\end{abstract}

\section{Introduction}

Severe short bowel syndrome is a devastating condition. Epidemiological data suggest that the incidence of severe short bowel syndrome is four in one million, the majority of whom are infants and young children (1). Of all the catastrophic conditions that lead to the subtotal loss of small intestine in early life, the most frequent are necrotizing enterocolitis (NEC) that endangers mainly low-weight new-borns, small intestinal volvulus as a result of intestinal malrotation, gastroschisis and "apple peel" syndrome of the small intestinal atresias. Other rare cases such as incarcerated congenital diaphragmatic hernia have also been reported (2).

After the loss of a certain length of the small bowel, transit time is shortened, the absorption of nutrients becomes ineffective, and malnutrition, dehydration and electro- 
lyte deficiency develop. The malabsorption of bile acids escalates diarrhoea and steatorrhea. The small intestine, in young childhood in particular, is capable of some compensation. The bowel adapts, crypts deepen, and villi become hypertrophic. However this process is slow and usually results in massive dilatation of the bowel. In dilated intestines the muscle constrictions are ineffective in narrowing the lumen, so the peristalsis becomes insufficient; the bowel content becomes stationary, which leads to translocation of bacteria, and sepsis (3). The management of short bowel patients is complex and requires both medical and surgical input from a multidisciplinary team (surgeon, gastroenterologist, dietician, pharmacist, nursing specialists) specialised in intestinal rehabilitation (4).

The aim of this review was to summarise the modern non-transplant surgical management of short bowel syndrome.

\section{Medical considerations Gastric hypersecretion}

A massive loss of intestine induces increased secretion of gastrin and gastric acid. This can lead to gastric ulcer and massive intestinal haemorrhage. Therefore, the introduction of $\mathrm{H} 2$-repector inhibitors or the more effective proton-pump inhibitors is essential (5). Octreotid has been used with variable success (6).

\section{Enteral feeding}

In infancy, breastfeeding or hydrolyzed formulas and middle chain triglycerides are introduced. Parenteral supplementation of fat-soluble and B12 vitamins (the latter is absorbed only in the terminal ileum) is always recommended (5). In older children food aversion makes high caloric feeding often difficult. Nasogastric tube (7) or endoscopically inserted percutaneous gastrostomy allows slow, continuous feeding even overnight. Surprisingly, short bowel patients tolerate complex carbohydrates better than simple sugars (8).

\section{Patients with high output stoma}

High levels of stoma discharge can be returned to the distal stoma (recycling), however microbiological safety should be seriously considered (9). If this is not possible then the stoma-deficit should be reinstated two hourly, parenterally. High output stomas may lead to severe loss of sodium, not recognizable in the serum electrolyte level, therefore urinary sodium should be monitored and if it is lower than $20 \mathrm{mM} / \mathrm{l}$ oral sodium supplementation is usually recommended (5).

\section{Reduced intestinal transit time}

Motility inhibitors are routinely used: codeine, morphine and loperamide effectively increase intestinal transit time. Cholestyramine binds free bile acids, reducing their laxative effects. A high fibre diet reduces diarrhoea by absorbing water (5).

\section{Parenteral nutrition}

Parenteral nutrition (PN) is usually introduced after recovery from the primary surgery when short bowel syndrome is expected. Long term home PN is available in many countries, but requires well-organized health care services and specialist nurses, who visit and teach the parents. It has been observed that with "low fat" PN (less than $1 \mathrm{~g} / \mathrm{kg}$ ) liver damage is far less frequent. Recently, omega-3 fatty acid PN has become preferred. However, liver failure is still one of the most feared complications of PN. PN requires long-term, safe central lines, which often become infected, dislodged or blocked. Even today the morbidity and mortality from long term PN is significant. The quality of life of the patients is rather low; their life is bound 
to the healthcare provider facility, although home parenteral nutrition, if possible, can improve life quality (10). Sepsis is common. Development and growth are most often delayed (11).

\section{Hormonal enhancement of bowel adaptation}

Clinical use of hormones such as epidermal growth factor or glucagon-like peptide 2 (GLP-2) is not yet widespread, however promising initial results have been published $(5,12,13)$. Jeppesen and Yazbeck (14) reported encouraging results with GLP-2 and with Teduglutide (a protease-resistant analogue of GLP-2 with prolonged biological activity) in adult Short Bowel Syndrome patients. Nutrient absorption was found to increase by $3.5 \%$. A significant increase in protein absorption was found, but no significant increase in carbohydrate absorption, and no significant change in fat absorption. Histological analysis of the small intestine demonstrated an increase in villus height and crypt depth, and more than $20 \%$ reduction in PN was observed $(13,14)$ Oral insulin supplementation was reported to decrease the need for parenteral nutrition in paediatric SBS patients in a pilot study (15).

\section{Surgical considerations \\ Prevention}

Early and accurate diagnosis of emergencies, such as malrotation, emergency surgery, careful bowel resection, second-look surgery, and avoidance of resection of the ileocaecal valve are the very important common sense factors.

\section{Vascular access management}

Even tunnelled, good quality, central venous catheters have a limited lifetime and they often become blocked, infected or broken and need replacement. The number of veins available for central catheter placement is limited. Careful indication and technique are mandatory. The percutaneous technique is preferred over surgical exploration (16). Antiseptic non-touch handling of catheters, and a regular 70\% ethanol catheter block may prevent catheter-sepsis. Broad-spectrum antibiotics may be effective to treat infected central lines, with urokinase to unblock them. If the removal of the catheter is unavoidable, the new catheter should be placed into the same vein, if possible.

\section{Small-bowel transplantation}

Intestinal transplantation is only available in certain countries. Although it is true that the short term (1 year) survival, especially with multi-organ (liver and intestine) transplantation, has increased dramatically in the last few years, in some high volume centres by up to $90 \%$, the long term (5 years) survival is significantly lower (50\%) and immunosuppressive therapy remains demanding for the patients and may go hand in hand with complications, thus this still remains the last resort of treatment (17).

\section{Autologous intestinal reconstructive surgery}

The non-transplant management of Short Bowel Syndrome, intestinal rehabilitation with autologous intestinal reconstruction surgery (AIRS) gives us the opportunity to shorten $\mathrm{PN}$ and/or restore enteral autonomy, and to avoid intestinal transplantation in an increasing number of patients. The use of AIRS began in the 1980-s, and its objective was to provide a surgical solution for the problems that occur in short bowel syndrome. The success rate of non-transplant management of short bowel patients has increased significantly over the last decade, and 
$92 \%$ overall survival rate has been reported recently and $91 \%$ of the surviving patients have been weaned from PN $(4,18,19)$. The major goals of AIRS are to increase transit time, improve motility of the dilated bowel, and increase the absorptive surface.

\section{Increase transit time}

The aim of initial interventions, such as antiperistaltic reverse segment, colon interposition and ileocaecal valve reconstruction valve procedures, was to increase transit time, allowing more time for absorption by creating controlled resistance.

\section{The Antiperistaltic "reverse" segment procedure}

A bowel segment, $10 \mathrm{~cm}$ long in adults and up to $8 \mathrm{~cm}$ in infants and children, reversed and reanastomosed antiperistaltically, is believed to slow down transit without causing bowel obstruction. This procedure is used when the absorption surface i.e. bowel length, is thought to be reasonable but transit is rapid, or it could be used in combination with other procedures (Fig. 1).
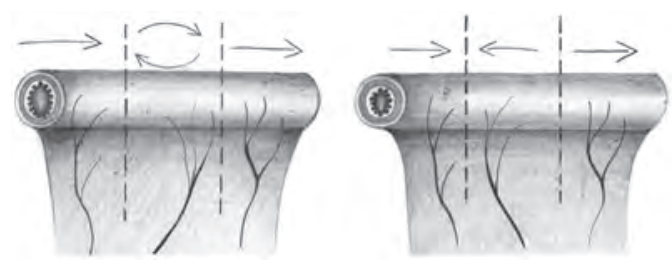

Fig. 1 Antiperistaltic "reverse" segment procedures.

\section{Colon interposition}

The method was developed by Hutcher et al. $(20,21)$. The transit time of the colon is longer than that of the small bowel. The benefit of interposing a colonic segment in the small bowel loop is that the chyme passes through the small bowel more slowly, giving the digestive enzymes more time for efficient diges- tion. Observations suggest that the histological structure of the colon also changes, and it adapts and becomes similar to the small intestine, further improving absorption (22, 23). Different lengths of colonic interposition were used. Glicket et al. (22) used 10-15 $\mathrm{cm}$ segments, while Garcia et al. (24) used a $24 \mathrm{~cm}$ segment. Four of the seven infants with isoperistaltic interposition survived.

\section{Ileocecal valve reconstruction}

As a result of the original condition (volvulus, NEC) the ileocaecal valve is often removed and an end-to-end ileo-colostomy is performed. The loss of the ileocaecal valve is believed to be well tolerated, however in a survey, one fourth of the non-short bowel patients were found to have persistent diarrhoea as a long-term complication (25). It is easy to understand that this may worsen the symptoms of short bowel syndrome. Some attempts have been made to reconstruct the ileocaecal valve, for example with intussuscepted small bowel nipple valves, but these valves require a very long segment $(6-7 \mathrm{~cm})$ of intussusception to become effective in short bowel syndrome (26). Histology analysis revealed that the anatomy of an ileocaecal valve does not resemble the classic sphincter anatomy. It is hypothesized that it could be easily reconstructed with the help of a double layered, 1-2 cm deep, end-to-side invaginated ileo-colostomy. However, this seems to be difficult and risky, and it has not yet been justified in clinical practice (27).

\section{Improve motility of the dilated bowel}

As a result of the natural bowel adaptation in short bowel syndrome, the intestine becomes dilated. In a large calibre segment the muscle constrictions are ineffective in narrowing the lumen, so peristalsis is insufficient; the bowel content becomes stationary, which leads to 
translocation of the bacteria. This is the main source of the sepsis experienced in short bowel patients. Surgical procedures have attempted to improve the motility of the severely dilated intestine. Excision of the "redundant" bowel wall has been associated with further loss of absorptive surface, and plication of the bowel wall is also not effective long term. Bianchi first developed a procedure where the dilated bowel was tailored to half of the calibre, without losing absorptive surface. Bianchi refashioned the short and dilated segment with impaired peristalsis to normal calibre but a longer intestine. This is beneficial, because a smaller calibre but longer bowel loop is able to provide adequate peristalsis, to prevent stasis and bacterial translocation, and allows a more sufficient transit time for absorption than a dilated and short segment $(3,4,28)$.

\section{Longitudinal Intestinal Lengthening and Tailoring (LILT)}

This technique is based on the fact that the vasa recta, running in the mesentery, divide before reaching the bowel, and supply one side or the other of the bowel. This way the arteries and veins can be separated from each other just before they reach the bowel wall, so the bowel can be divided into two longitudinal halves, conserving a good blood supply. From the two halves of bowel wall, it is possible to tailor new bowel segments, which have a lumen half the original length, and their joint length is twice as long as the original bowel. However this procedure is surgically challenging and only surgeons with significant experience with this technique are able to execute it safely (18). The overall survival rate is reported to be between 30\%-100\%, and the ability to wean from $\mathrm{PN}$ varied from 28\%-100\% in different series with LILT (29, 30-33). Complications such as stenosis at the hemiloop anastomosis, inter-loop fistula, loss of the hemi-loop from vascular compromise and recurrent dilatation, have been reported (34, 35). A systematic literature review of the Bianchi and STEP procedures in 2013 reported overall survival of $89 \%$, with no significant difference between the two procedures. The Bianchi procedure has been found to have higher rate of weaned patients, 55\% vs. $48 \%$, however the Bianchi procedure has been associated with a higher rate of patients receiving transplantations: $10 \%$ vs. $6 \%$ (33) (Fig. 2).

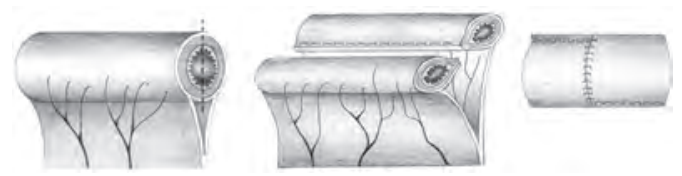

Fig. 2. Longitudinal Intestinal Lengthening and Tailoring.

\section{Serial Transverse Enteroplasty (STEP)}

This procedure, developed in 2003, is much simpler than the Bianchi operation, there is no need for the challenging disassociation of the mesentery, the extent of the lengthening and the narrowing of the intestine is adjustable within limits (36), but its disadvantage is that the concentric fibres become longitudinal and the longitudinal fibres become concentric, thus making the peristaltic movements uncertain (37). This might be the explanation for the usual bowel dilatation after STEP (38). The STEP procedure has been performed successfully in many centres. Recently, Jones Ba et al. (39) reported the results of 111 consecutive patients enrolled in the international STEP data registry. The overall post STEP mortality was $11 \%$, and $47 \%$ of the group attained full enteral nutrition after the procedure. However, patients with longer pre-STEP bowel length were significantly more likely to achieve enteral autonomy (39) (Fig. 3). 

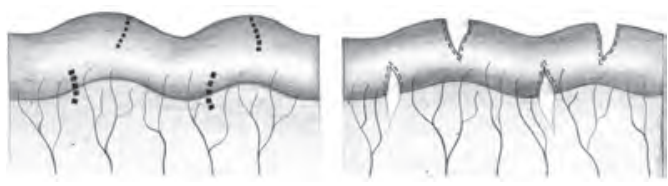

Fig. 3 Serial Transverse Enteroplasty (STEP).

\section{Spiral Intestinal Lengthening and Tailoring (SILT)}

The spiral intestinal lengthening is a new alternative. It barely affects the mesentery, it is simple and does not change the orientation of the fibres dramatically. The heart of the procedure is that the bowel wall is cut along a spiral line, twisted and then lengthened longitudinally to tailor it into a tube again. The mesentery is also incised where it meets the spiral cut-line (37). The procedure was tested in animals (40) and two independent successful human applications have also been reported $(41,42)$. The SILT technique also seems to have urological application and it seems suitable for creating long Mitrofanoff channels for intermittent catheterisation (43) (Fig. 4).
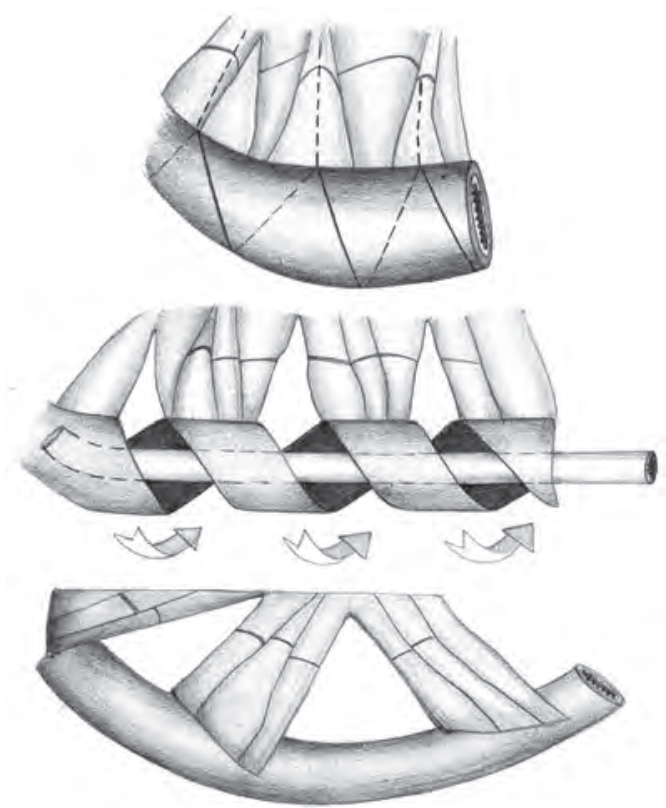

Fig. 4 Spiral Intestinal Lengthening and Tailoring (SILT).

\section{Increasing the absorptive surface}

Mechanical tissue expansion is widely used in plastic surgery for autologous skin transplantation. Mechanical force (controlled pressure or traction) has been proven to increase the absorptive surface and the enterocyte mass of the small intestine $(44,45,46)$. This, and the success of the tailoring and lengthening procedure, have led to the idea of controlled bowel expansion (47).

\section{Controlled bowel expansion}

In the course of the procedure, a catheter (stoma catheter) is placed into the lumen of the bowel, and a controlled obstruction is used to expand the intestine, obtaining a greater absorbing surface. The expanded dilated bowel loses its motility, but it can be reconstructed using lengthening and tailoring procedures, and refashioning of the dilated short bowel to a normal calibre, but longer segment, without losing absorptive surface. The catheter stoma also gives us the opportunity to recycle the bowel content from the proximal to the distal stoma, reducing the need for PN and atrophy of the distal stoma (47). There are experiments in progress to develop endoluminal devices for intestinal lengthening but these are still far away from safe clinical application (46).

\section{Combination of the procedures}

AIRS procedures could be combined and tailored to the individual needs of the patients. Controlled bowel expansion, with tailoring and lengthening procedures and with ileocaecal valve reconstruction, seems to be most logical sequence in a severe short bowel condition.

\section{Conclusion}

With the advancement of PN, enteral feeding and autologous AIRS, the survival of 
short bowel patients has improved, and the length of PN needed reduced significantly over the last decade. Intestinal bowel rehabilitation and autologous intestinal reconstruction should be considered as first line management in short bowel patients. The establishment of national bowel rehabilitation centres should be considered.

Conflict of interest: The author declares that he has no conflict of interest.

\section{References}

1. Lennard-Jones JE. Indications and need for longterm parenteral nutrition: implications for intestinal transplantation. Transplant Proc. 1990;22:2427-9.

2. Cserni T, Polonkai E, Torok O, Nagy A, Pataki I, Long AM, et al. In utero incarceration of congenital diaphragmatic hernia. J Paediatr Surg. 2011;46:551-3.

3. Bianchi A, Morabito A. The dilated bowel: a liability and an asset. Semin Pediatr Surg. 2009;18:249-57.

4. Coletta R, Khalil BA, Morabito A. Short bowel syndrome in children: surgical and medical perspectives Semin Pediatr Surg. 2014;23:291-7.

5. Nightingale J, Woodward JM; Small Bowel and Nutrition Committee of the British Society of Gastroenterology. Guidelines for management of patients with a short bowel. Gut. 2006;55 (Suppl 4):iv1-12.

6. Keefe SJ, Haymond MW, Bennet WM, Oswald B, Nelson DK, Shorter RG. Long-acting somatostatin analogue therapy and protein metabolism in patients with jejunostomies. Gastroenterology. 1994;107:379.

7. Joly F, Dray X, Corcos O, Barbot L, Kapel N, Messing B. Tube feeding improves intestinal absorption in short bowel syndrome patients. Gastroenterology. 2009;136:824.

8. Matarese LE. Nutrition and fluid optimization for patients with short bowel syndrome, JPEN J Parenter Enteral Nutr. 2013;37(2):161-70.

9. Pataki I, Szabo J, Varga P, Berkes A, Nagy A, Murphy F, et al. Recycling of bowel content: the importance of the right timing J Pediatr Surg. 2013; 48:579-84.

10. Ricour C, Gorski AM, Goulet O, de Potter S, Corriol $\mathrm{O}$, Postaire $\mathrm{M}$, et al. Home parenteral nutri- tion in children: 8 years of experience with 112 patients. Clin Nutr. 1990;9(2):65-71.

11. Van Gossum A, Cabre E, Hébuterne X, Jeppesen P, Krznaric Z, Messing B, et al. ESPEN Guidelines on Parenteral Nutrition: gastroenterology. Clin Nutr. 2009; 28:415-27.

12. Sigalet DL, Martin GR, Butzner JD, Buret A, Meddings JB. A pilot study of the use of epidermal growth factor in pediatric short bowel syndrome. J Pediatr Surg. 2005;40:763-8.

13. Jeppesen PB, Hartmann B, Thulesen J, Graff J, Lohmann J, Hansen BS, et al. Glucagon-like peptide 2 improves nutrient absorption and nutritional status in short-bowel patients with no colon. Gastroenterology. 2001;120:806-15.

14. Yazbeck R. Teduglutide, a glucagon-like peptide-2 analog for the treatment of gastrointestinal diseases, including short bowel syndrome. Curr Opin Mol Ther. 2010;12(6):798-809.

15. Shamir R, Kolacek S, Koletzko S, Tavori I, Bader $\mathrm{D}$, Litmanovitz I, et al. Oral insulin supplementation in paediatric short bowel disease: a pilot observational study. J Pediatr Gastroenterol Nutr. 2009;49:108-11.

16. McBride KD, Fisher R, Warnock N, Winfield DA, Reed MW, Gaines PA. A comparative analysis of radiological and surgical placement of central venous catheters. Cardiovasc Intervent Radiol. 1997;20(1):17-22.

17. Grant D, Abu-Elmagd K, Reyes J, Tzakis A, Langnas A, Fishbein T, et al. 2003 report of the intestine transplant registry: A new era has dawned. Ann Surg. 2005;241:607-13.

18. Bianchi A. Intestinal loop lengthening-a technique for increasing small intestinal length. J Pediatr Surg. 1980;15:145-51.

19. Khalil BA, Ba'ath ME, Aziz A, Forsythe L, Gozzini $S$, Murphy $F$, et al. Intestinal rehabilitation and bowel reconstructive surgery: improved outcomes in children with short bowel syndrome. J Pediatr Gastroenterol Nutr. 2012;54:505-9.

20. Hutcher NE, Salzberg AM. Pre-ileal transposition of colon to prevent the development of short bowel syndrome in puppied with 90 percent small intestinal resection. Surgery. 1971;70:189-97.

21. Hutcher NE, Mendez-Picon G, Salzberg AM. Prejejunal transposition of colon to prevent the development of short bowel syndrome in puppies with 90 per cent small intestine resection. J Pediatr Surg. 1973;8:771-7. 
22. Glick PL, de Lorimier AA, Adzick NS, Harrison MR. Colon interposition: an adjuvant operation for short-gut syndrome. J Pediatr Surg. 1984;19:719-25.

23. Sidhu GS, Narasimharao KL, Rani VU. Morphological and functional changes in the gut after massive small bowel resection and colon interposition in rhesus monkeys. Digestion. 1984;29:47-54.

24. Garcia VF, Templeton JM, Eichelberger MR. Colon interposition for the short bowel syndrome. J Pediatr Surg 1981;16:994-5.

25. Folaranmi S, Rakoczy G, Bruce J, Humphrey G, Bowen J, Morabito A, et al. Ileocaecal valve - how important is it? Pediatr Surg Int. 2011;27:613-5.

26. Cserni T, Pap Szekeres J, Furka I, Németh N, Józsa T, Mikó I. Hydrostatic characteristics of the Ileocolic valve and intussuscepted nipple valves: an animal model. J Invest Surg. 2005;18:185-91.

27. Cserni T, Paran S, O’ Donnell AM, Puri P. New insight into the neuromuscular anatomy of the ileocaecal valve. Anat Rec. 2009;292:254-61.

28. Jones BA, Hull MA, McGuire MM, Kim HB. Autologous intestinal reconstruction surgery. Semin Pediatr Surg. 2010;(1):59-67.

29. Bianchi A. From the cradle to enteral autonomy: the role of autologous gastrointestinal reconstruction. Gastroenterology. 2006;130:S138-46.

30. Waag KL, Hosie S, Wessel L. What do children look like after longitudinal intestinal lengthening. Eur J Pediatr Surg. 1999;9:260-2.

31. Thompson JS, Pinch LW, Young R. Long-term outcome of intestinal lengthening. Transplant Proc.2000;32:1242-3.

32. Hosie S, Loff S, Wirth H. Experience of 49 longitudinal intestinal lengthening procedures for short bowel syndrome. Eur J Pediatr Surg. 2006;16:171-5.

33. King B, Carlson G, Khalil BA. Intestinal bowel lengthening in children with short bowel syndrome: systematic review of the Bianchi and STEP procedures. World J Surg. 2013;37:694-704.

34. Thompson JS, Pinch LW, Murray N. Experience with intestinal lengthening for the shortbowel syndrome. J Pediatr Surg. 1991;26:721-4.

35. Walker SR, Nucci A, Yaworski JA. The Bianchi procedure: a 20-year single institution experience. J Pediatr Surg. 2006;41:113-9.

36. Kim HB, Fauza D, Garza J, Oh JT, Nurko S, Jaksic T. Serial transverse enteroplasty (STEP): a novel bowel lengthening procedure. J Pediatr Surg. 2003;38(3):425-9.

37. Cserni T, Takayasu H, Muzsnai Z, Varga G, Murphy F, Folaranmi S, et al. New idea of intestinal lengthening and tailoring. Pediatr Surg Int. 2011;27:1009-13.

38. Kang KH, Gutierrez IM, Zurakowski D, Diperna S, Buonomo C, Kim HB, et al. Bowel re-dilation following serial transverse enteroplasty (STEP). Pediatr Surg Int. 2012;28:1189-93.

39. Jones BA, Hull MA, Potanos KM, Zurakowski D, Fitzgibbons SC, Ching YA, et al. Report of 111 consecutive patients enrolled in the International Serial Transverse Enteroplasty (STEP) Data Registry: a retrospective observational study. J Am Coll Surg. 2013;216(3):438-46.

40. Cserni T, Varga G, Erces D, Kaszaki J, Boros M, Laszlo A, et al. Spiral intestinal lengthening and tailoring - first in vivo study. J Pediatr Surg. 2013; 8:1907-13.

41. Cserni T, Biszku B, Guthy I, Dicso F, Szaloki L, Folaranmi S, et al. The first clinical application of the spiral intestinal lengthening and tailoring (SILT) in extreme short bowel syndrome. J Gastrointest Surg. 2014;18:1852-7.

42. Alberti D, Boroni G, Giannotti G, Parolini F, Armellini A, Morabito A, et al. "Spiral intestinal lenghtening and tailoring (SILT)" for a child with severely short bowel. Pediatr Surg Int. 2014;30:1169-72.

43. Cervellione RM, Hajnal D, Varga G, Rakoczy G, Kubiak R, Kaszaki J, et al. New alternative Mitrofanoff channel based on spiral intestinal lengthening and tailoring. J Pediatr Urol. 2015;11:131.e1-5 2015.

44. Collins J 3rd, Vicente Y, Georgeson K, Kelly D. Partial intestinal obstruction induces substantial mucosal proliferation in the pig. J Pediatr Surg. 1996;31:415-9.

45. Safford SD, Freemerman AJ, Safford KM, Bentley $\mathrm{R}$, Skinner MA. Longitudinal mechanical tension induces growth in the small bowel of juvenile rats. Gut. 2005;54:1085-90.

46. Shekherdimian S, Panduranga MK, Carman GP, Dunn JC. The feasibility of using an endoluminal device for intestinal lengthening. Pediatr Surg. 2010;45:1575-80.

47. Murphy F, Khalil BA, Gozzini S, King B, Bianchi A, Morabito A. Controlled tissue expansion in the initial management of the short bowel state. World J Surg. 2011;35:1142-5. 